\title{
Learning from leisure: Developing nature connectedness in outdoor education
}

\author{
Marg Cosgriff - The University of Waikato, New Zealand
}

\begin{abstract}
$T$ he "greening" of outdoor education has received increasing attention from educators in Aotearoa-New Zealand and internationally. Given contemporary global concerns about the scale of environmental issues and the associated recognition that educating for sustainability is a matter of urgency, the continuing exploration of pedagogies promoting human connection to nature is arguably a central concern for outdoor educators. This paper contributes to professional dialogue about outdoor education pedagogies that may facilitate the development of students' connectedness to, and care for, non-human nature. It draws from an interpretative research project that explored the meanings of nature-based leisure for eleven women aged 40 to 65 years. Findings from that research highlighted an important interplay between women's conceptions of nature and their participation in leisure. The paper directs attention to three interconnected pedagogical principles that are teased from the women's stories: repeated immersion in local nature environments, the decentring of traditional performance discourses, and critical reflection. These are presented as key considerations for outdoor education teachers and teacher educators in promoting nature connectedness and care. Recommendations are made for outdoor education researchers and teacher educators for future research directions.
\end{abstract}

\section{Introduction}

I just love the feel of the elements on me and that's why I loved waka ama (outrigger canoe) paddling. You couldn't be in a better place and have all the elements around you: Mauao (Mount Maunganui) down the end on the water, you had the moana (sea) there. You had the wind blowing and the sun on you and sometimes the moon cos you did it at night. So I just loved the whole idea of being outside. You go out into the ngahere (forest), just walking and feeling... I just love nature, that feeling, the natural elements around me... (Tiana)

At an outdoor recreation and education conference in 2008, some preliminary findings from a study of women's nature-based leisure that are drawn on in this paper and which Tiana's quote above is from, were presented. In particular, the meanings of the terms nature and outdoors was explored, with excerpts from interviews used to voice and discuss women's understandings. A distinctive memory for me from the presentation was when a member of the audience posed a question along the lines of "Nice stories about women's meanings of nature...but so what?" 
One starting point for responding to this question and for setting the scene for this paper is to acknowledge that student learning does not occur just within the confines of the school setting. An array of research (see for example MacPhail, Collier, \& O'Sullivan, 2009; Wright, MacDonald, \& Groom, $2003^{2}$ ) examining young people's participation in, and experiences of, physical activity in leisure time has raised fruitful pedagogical questions for physical education in schools. For example, Flintoff and Scraton (2001) revealed the disjuncture between young women's wider physical activity experiences out of school and school-based physical education experiences. Unlike physical activity experiences out of school, physical education lacked an obvious rationale and many young women felt they did not develop skills, were not physically challenged, or did not have adequate choice about the activities that were to be participated in. Critical questions about why these young women were "... at best, indifferent to PE; at worse, hostile" (Flintoff \& Scraton, 2001, p. 18) even when they were physically active outside of school, call out for a rethinking of pedagogical practice.

Leisure research thus may provide productive insights for educators about the discourses and practices that shape perceptions, attitudes, and experiences of physical activity. In this paper, insights from women's nature-based leisure stories are used to provide a prompt and foundation for engaging with particular pedagogical dilemmas and challenges pertinent to contemporary outdoor education, centring on notions of connectedness with/to nature. The research project discussed here examined the meanings and experiences of nature and nature-based leisure for a group of women from Aotearoa-New Zealand. Of central interest was women's expressions of connectedness with nature and the ways in which this impacted on both their outdoor leisure practice and their environmental actions in everyday life. While interaction in and with nature is commonly cited as being central to understanding humans' relationships with the world (Lugg, 2007), it is less clear what teaching and learning processes actually promote the knowledge, empathy, and connectedness considered (see for example Martin, 2008) to be integral to positive and sustainable human and non-human nature relationships.

Looking beyond outdoor education's immediate theoretical backyard, this paper therefore turns to women's nature-based leisure stories for pedagogical insights that might support students to develop similarly proactive, caring relationships. The following overview of contemporary curriculum and pedagogy in outdoor education in Aotearoa-New Zealand identifies the diverse nature of outdoor education in school settings and draws attention to recent moves directed towards the greening of outdoor education in Aotearoa-New Zealand and Australia. Literature is introduced that has identified the need to disrupt anthropocentric notions of nature and the outdoor world (Hill, 2010b), the limitations of decontextualised activity based programmes (Brown, 2008), and the ongoing tensions embedded in using skill-focused outdoor pursuits (Irwin, 2008). Examples of 'green' pedagogy drawn from current outdoor education programmes are foregrounded as a reference point to considering specific findings of research focusing on women's nature-based leisure. Discussion of the research undertaken and more specifically, data arising, then centres on three pedagogical principles that I contend have a potentially key role to play in promoting nature connectedness in outdoor education. While none of the principles can be claimed to be new and indeed, may be notably familiar to pedagogues in various fields, I argue that women's stories give weight to calls for their sustained application in outdoor education. 


\section{Outdoor education in Aotearoa - New Zealand}

Outdoor education is an established part of school programmes in Aotearoa-New Zealand. It is one of seven key areas of learning in the Health and Physical Education (HPE) learning area within the revised New Zealand Curriculum (Ministry of Education, 2007) ${ }^{3}$, and finds further expression within education outside the classroom (EOTC) ${ }^{4}$. Across primary and secondary schools nationally, an enduring belief in the value of outdoor learning is variously evidenced in the provision of a diverse range of outdoor education experiences as part of curricula, co-curricula, and extracurricular programmes. Clarifying precisely what constitutes outdoor education in Aotearoa-New Zealand is, however, not straightforward. Over a decade ago, Boyes (2000) suggested that there was a "lack of semantic agreement" (p. 76) in regards to outdoor education terminology, and diverse understandings of outdoor education still prevail (Hill, 2010b). While the focus of this paper is more specifically outdoor education within HPE, no actual definition of outdoor education is given in the national curriculum statement. Reference to the previous HPE curriculum (Ministry of Education, 1999) as well as definitions in the recently published national EOTC guidelines (Ministry of Education, 2009), suggests however that outdoor education focuses on "particular aspects of outdoor learning, such as adventure activities, outdoor pursuits, and relevant aspects of education for sustainability" (Ministry of Education, 2009, p. 71).

While diversity and local variation in outdoor education in Aotearoa-New Zealand is recognised, it has been suggested nevertheless that "commonly held notions of what comprises outdoor education" persist (Irwin, 2008, p. 36). As many authors have highlighted, a sustained focus on personal and social development outcomes has historically favoured the provision of particular pedagogical experiences over other possibilities (Brown, 2008; Brown \& Fraser, 2010; Cosgriff, 2008; Lynch, 2006; Zink \& Boyes, 2006). Zink (2003) clearly articulated this when she drew links between the widespread usage of outdoor pursuits and adventure activities in school programmes, personal development outcomes, society's fascination with adventure, and risk and challenge discourses. As she suggested, "The ongoing focus on outcomes such as self-esteem and 'character building' that permeate much of outdoor education rhetoric tend to foreground the role of challenging activities as the means of achieving this" (p. 61). Skills-based, outdoor pursuits can thus become the takenfor-granted content of many outdoor education classes, and unintended pedagogical consequences may arise. Brown and Fraser (2010) have noted, for example, the paradoxical reduction in learner decision-making and negotiation when 'risky' activities necessitate that "experts provide specialist advice and controls on participation" (p. 12).

In parallel, other pedagogical debates have been emerging specifically relating to the marginalising of nature in many outdoor education programmes. Calls to 're-place' or 're-earth' outdoor education so that student connectedness to, and care for, non-human nature is a more central pedagogical concern have become increasingly audible (see for example Brown, 2008, 2010; Cosgriff, 2008; Hill, 2008, 2010b; Irwin, 2008, 2010; Straker, 2010 for further discussion in the Aotearoa-New Zealand context). Some distinctive themes run through contemporary professional dialogue and debate about 'green' outdoor education in Aotearoa-New Zealand and Australia. For example, the pervasiveness of anthropocentric assumptions and practices, wherein humans are considered to 
be separate from, and above, non-human nature has been repeatedly noted (for example Cosgriff, 2008; Hill, 2009, 2010b; Payne \& Wattchow, 2008). Nature tends to be viewed as a "functional room" or "arena" (Andkjær, 2010), a gymnasium for personal development, immediately useful to humans only in so far as providing a resource for the achievement of programme goals that may have little to do with developing knowledge about the distinctiveness of the specific environment itself. The "blind spots" anthropocentrism causes may "...unintentionally reinforce the view that wild places have value only if they are useful to humans" (Brookes, 1994, p. 30).

Brown's (2008) description of "decontextualised activity based" programmes (p. 9) has distinct parallels with these ideas: "generic" or "novel" activities being used for personal or social development, in a context-free locale. Furthermore, Brown (2008) argues decontextualised activity approaches generally use activities with little attention to seasonal, environmental, or geographical variations (p. 9), and use unfamiliar locations that are "largely irrelevant" to programme purposes. In short, this generalised approach not only overlooks place and participants' relationships with particular places, but also "...treats the self, others and environment as on the one hand applying to all and on the other, as applying to none" (Brown, 2008, p. 9).

Another pedagogical debate centres on the question of whether traditional outdoor adventure activities can be used to engender the environmental connectedness that is widely considered to be an integral aspect of sustainable human and non-human nature relationships. This is particularly pertinent to the research reported in this paper. In the Australian context, Lugg (2004) has noted professional debate about the problematic nature and social construction of some adventure activities in regards to environmentally empathetic practice. The relevance of 'imported' outdoor adventure activities for 'homegrown' outdoor education that promotes student understanding of, and connectedness to, specific natural and cultural environments had also been widely debated (Lugg, 2004; Payne, 2005; Payne \& Wattchow, 2008). Also speaking from an Australian context, Payne and Wattchow (2008) contended that the "...interface of competence, equipment, and technological demands" of many common outdoor activities meant that "Objectified nature and its instrumentalized spaces tend to be 'passed through' or 'over' as distinct from 'paused' or 'dwelled' in” (p. 25). Lugg's question of whether it is possible to avoid an instrumental approach to nature when outdoor adventure activity is the means of interaction with natural environments thus appears to sum up a notable professional concern.

While the potential of outdoor adventure pursuits for promoting human and non-human nature connectedness and environmentally attuned interaction has clearly been questioned, the converse has also occurred. Martin (2004) for example, suggests that for some tertiary outdoor education students, adventurous outdoor activities are central to their enjoyment of nature and their motivation for continued involvement and may be "...one of the most effective educational tools available for developing positive relationships between humans and nature, particularly when blended with opportunities for reflection" (p. 26). Andkjær (2010) has similarly stated that adventure activities may represent and allow for a more "bodily sense of place" (pp. 19-20), while studies in recreational contexts (see for example Brymer \& Gray, 2009; Thompson, Hutson, \& Davidson, 2008) also lend weight to the proposition that it is through the experiencing of adventure activities that a deep embodied connectedness or care for nature may be developed. 
From a pedagogical perspective, Lugg's (2007) emphasis is that "learning from the experience of 'nature' is significantly influenced by the nature of the experience" (p. 105, italics in original). In this regard, attention has been drawn to a number of points including the importance of affective and sensory learning in promoting environmental sensitivity or place connectedness (for example Martin, 2004, 2007, 2008; Wattchow, 2008); the need for extended periods in outdoor environments (for example Martin, 2005; Rickinson, Dillon, Teamey, Morris, Mee Young, Sanders, \& Benefield, 2004) and/or repeated time in a specific place (Hill, 2010b; Martin, 2004). Payne and Wattchow (2008) have suggested the value of a "slow pedagogy" for "placing' education in nature" (p. 25) and Brookes (1994) similarly emphasised the importance of gaining an intimate, localised tacit knowledge of particular environments. Other pedagogical points emerging from literature include the importance of deliberate planning and facilitation for environmental objectives (Preston, 2004; Thomas, 2005); the need for teachers to harness serendipitous learning opportunities (Lugg, 2007; Thomas, 2005); the value of a seamless integration of environmental and outdoor activities rather than a compartmentalised programme approach (Preston, 2004); and the provision of opportunities for students to critically reflect on how they have come to 'know' nature and how to interact in and with nature in sustainable ways both in outdoor education and daily living (for example Hill, 2008, 2010c; Martin, 2008). An experiential examination of the social, cultural, and environmental histories, stories, and meanings of particular places (Irwin, 2010; Martin, 2007; Preston, 2004; Stewart, 2008) has also been suggested to be central to understanding and promoting relationships between people and the land.

Thus, considerable commentary exists that engages with, and to some degree problematises, the dynamic between outdoor education, nature, and pedagogy. Further prompts for teachers in Aotearoa-New Zealand to explore this dynamic arise from the revised New Zealand Curriculum (NZC) (Ministry of Education, 2007). This establishes the "direction" for teaching and learning in English-medium New Zealand schools ${ }^{5}$ and specifically identifies "ecological sustainability" as one of the eight values ${ }^{6}$ to be "encouraged, modelled, and explored" and to be manifest in any school's "philosophy, structures, curriculum, classrooms, and relationships" (p. 10). People and their relationships and interactions with non-human nature and the communities in which they live is also implicit in almost every one of the eight learning area statements and finds direct expression in achievement objectives in a number of learning areas including health and physical education, science, and social sciences. In a similar vein, the English translation of Te Marautanga o Aotearoa (Ministry of Education, 2008) the curriculum for Mãori medium schools in AotearoaNew Zealand, identifies the centrality of learners' relationships with their world to student learning and the educational process. One of the five "overarching principles" of Te Marautanga o Aotearoa is "Environmental health is personal health" wherein the school-based curriculum supports "a sustainable environment; learning pathways which enable the learner to engage purposefully with the environment; holistic teaching programmes; learner engagement with their environment" (p. 7). Strands and achievement objectives across the different learning areas also directly target human relationships with the environment. For example in the learning area of Hauora ${ }^{7}$, the strand of Taiao (Health and the environment) suggests the provision of learning opportunities for students to explore "ideas about the close and enduring relationship between people and the natural environment, exploring ways to lessen harmful environmental impacts" (p. 40). 
In sum, this section has identified that promoting sustainable human and non-human nature connectedness is an increasing professional concern for outdoor educators in Aotearoa-New Zealand. Attention now turns to exploring women's nature-based leisure and the pedagogical insights that may be drawn from their stories.

\section{What can we learn from women's leisure?}

In this section, I selectively draw on findings from the women and nature-based leisure study that have been more fully reported in an earlier paper (Cosgriff, Little, \& Wilson, 2010). The study pursued the outdoor leisure experiences of a group of eleven women (aged 40-65) living in the Bay of Plenty and Waikato regions of Aotearoa-New Zealand. It aimed to explore women's nature-based leisure, with semi-structured interviews used to examine the women's meanings and descriptions of nature, their current and past nature-based leisure experiences, and the influences on and impact of these in their lives. The women's individual life circumstances, such as their household living arrangements, employment, or family structures varied considerably. Ten women were Pãkehã New Zealanders ${ }^{8}$ and one was a Mãori woman. Gardening, beach or bush walking, tramping, sea and lake swimming, body surfing, kayaking, mountain biking, skiing, and sitting relaxing in outdoor environments like parks or at the beach were some of the main outdoor leisure activities the women currently participated in.

Our intention in interviews was to provide a space where women could define the meanings of nature and their nature-based leisure from their own standpoint, with the second interview specifically providing the opportunity for women to reflect further on what they had talked about in the first interview and for meaning to be clarified. All interviews were taped, transcribed, and analysed for key themes. Each woman chose a pseudonym to use except Tiana, who wanted to use her own name to reflect and emphasise that it was 'her story'.

\section{Women's nature meanings and connectedness}

The wider analysis of women's meanings of nature revealed a complexity and depth of description (Cosgriff, Little, \& Wilson, 2010). Nature was thus sensory, emotional, and spiritual in its description. The colours, smells, detail, "feel", and "sense" of nature were frequently talked about alongside the physicality of the leisure activity. Dynamic and holistic understandings of nature shaped by and through leisure activity rather than one dimensional definitions were evident (Cosgriff, Little, \& Wilson, 2010), as was a sense of being "lucky", "grateful", or "privileged" for being able to recreate in sensory, nature spaces. Furthermore, a connectedness with nature was expressed which meant that most women clearly described themselves as part of, rather than separate to nature. This relational connectedness that was fostered through naturebased leisure, meant women repeatedly noted that nature was "part of me". Tiana explained that her connection and her sense of belonging to the land as a Mãori woman, "all came down to whakapapa” (genealogy) (Cosgriff, Little, \& Wilson, 2010, p. 26). This expression of kinship and interdependence with the land that is customary for Mãori (Mead, 2000; Taukamo, 2008), has 
been widely noted as common to other indigenous people (see for example Harrison \& Birrell, 2005; Martin, 2005; Matunga, 1995 for discussion in an outdoor education context).

In describing the reciprocity that appeared to be at least in part a 'natural' consequence of this connectedness, many women articulated an active regard and caring for nature both when they were engaged in leisure activity and in everyday living (Cosgriff, Little, \& Wilson, 2010). For example, when tramping, Amy commented that she did not just "rip through the bush" when there were no defined paths or tracks. Instead, she looked to find the "natural pathway in the bush...to be respectful to the bush". When sea or lake kayaking, Rae acknowledged that there was no need for her to "conquer" nature nor race through it, as pleasure came from just being on the water and her love of the "physical motion of paddling and being out there". In regard to everyday living, Mary noted that her connections and love for the outdoors meant that she did not want to see it all "wrecked" and needed to contribute and "put something back in for future generations". Laurel laughed at her "thrifty" penchant for using and reusing things rather than "just chucking everything out", and recalled all the "old remedies or tricks" that she used around the house and garden rather than "modern sprays and things". Other actions taken to "put something back in" to enact the sense of responsibility that was felt for caring for nature included recycling, composting, gardening, preserving fruit, walking rather than driving, weighing up whether the purchasing of goods was a "real need", and active participation in community-based environmental projects. Amy neatly summed up this general sense of being able and willing to contribute to caring for non-human nature:

I can make a difference but I know that sometimes people don't believe that as one small individual with one little voice they can make a difference to something, but you can... Recently I went to the quarry that is being rehabilitated at Te Puna and it was just apparently a desolate site, a quarry that had been quarried out and left. A couple of older ladies, made it their mission to change it to something better and they just started to build gardens and then other people joined them and now there's lots of people joining them and it's turning into something quite different... so everybody can make a difference. (Amy)

\section{Time in, and with, nature}

Digging further into women's descriptions of their motivations for nature-based leisure and the place and 'value' that it held in their lives revealed that leisure time in and with nature was considered to be "essential", "really important", or "significant" for most women's emotional, physical, and spiritual wellbeing. Everyday life circumstances such as family and work commitments however meant that nature-based leisure in some settings, particularly the remote or multi day, could not just happen on a whim or a needs-based basis. While tramping, skiing, kayaking, and other activities in far-flung locations were talked about and obviously savoured by many women, the need to be participating in nature-based leisure on a frequent if not daily basis was evident. Eliza walked around a local estuary every morning at dawn; Prue, Amy, Grace, Laurel, and Rae gardened regularly; and May, Mary, and George walked as much as they could in local park and bush environs in the region. Five of the seven women who lived in the Bay of Plenty region talked specifically about leisure activity around Mauao (Mount Maunganui), a coastal landmark of special significance to both Mãori and Pãkehã in the local region. Everyday, familiar local spaces and places were thus a primary site for the leisure activity that fostered the connectedness with nature that women expressed. 


\section{Being and doing...not just doing}

It (waka paddling) was a bodily and also a spiritual experience. It was very much about being in a rhythm, like creating an organism within the bigger organism really. Like it was just like that whole... when it came in sync...it was about being a part of something just way greater than you. (May)

While women participated in a range of nature-based activities in an array of settings, it was repeatedly noted by many women that nature was central to the leisure experience rather than just a backdrop for physical participation (Cosgriff, Little, \& Wilson, 2010). This was evident in some women's negative responses to using indoor sites like a gym to engage in physical activity, as well as their discussion about the importance of the 'being' and 'doing' components of their memorable nature-based leisure experiences. Apart from the instance of a life threatening or particularly risky situation when attention needed to be singularly focused on survival rather than nature itself, it appeared that it was the physicality of the 'doing' in tandem with the 'being' in nature that collectively created the meaningfulness of the leisure experience and their deeply-felt sense of connectedness to nature (Cosgriff, Little, \& Wilson, 2010). Prue spoke of her growing attention to seeing the detail and history in nature when she was tramping or on the coast, commenting that the more that someone knows about a particular environment, the more the "land's stories" are noticed. May recounted two recent experiences she had when walking by herself in the bush, where she had literally turned around and seen what she described as the "energy body of the bush" where the bush had been "... folding out on itself like a big soft wringer washing machine". Harking back to her upbringing on a farm, she explained that in childhood the nature-based experience would have been understood as purely a physical one, however since she was about twenty it had become "much more of a whole". This made it hard for her to separate out the physical and nature dimensions of nature-based leisure as the "whole picture just feels good". In a somewhat similar way, Grace noted that being in nature "restored her soul", suggesting that this was due to a combination of the physicality of movement, and the "communing with nature" and recognising the connections therein. A number of women referred directly to being "drawn" to the local beaches as much for the feelings of calmness, "at one-ness", and clarity that were generated even if they were just sitting watching the waves. Like other women, Tiana specifically mentioned the "spiritual" and "healing" dimensions of nature places, describing her need to just go and sit beside Mauao in times when she needed "strength and sustenance".

While the physicality of the leisure experience was important to women and brought satisfaction and pleasure, the varied accounts of women's experiencing of nature suggested that physical activity did not necessarily have to be 'extreme', 'fast', or technologically complex for nature-based leisure to have meaning. In short, "nature and 'being' in nature, was as integral to the experience as the physical expression of 'doing”" (Cosgriff, Little, \& Wilson, 2010, p. 27). Thus the sensory and spiritual dimensions appeared to be inextricably interwoven with the physical and the kinaesthetic dimensions in many explanations of the meanings of nature and nature-based leisure in women's lives. Samantha's reflection that she did not appreciate the outdoors or "the view" as a child when "dragged" on tramps with her father, and May's point that childhood nature-based experiences were largely about "loving the physical" illustrate changing perceptions about the sensory and spiritual components of nature and nature-based leisure activity over the course of some women's lives (Cosgriff, Little, \& Wilson, 2010). 


\section{Asking hard questions}

On a number of occasions, women made an obvious effort to unravel or question the ways in which their leisure behaviours aligned with their espoused connectedness to nature and particular nature places, or how they might better enact their love for nature and nature-based leisure in everyday living. Prue debated with herself when she did not have time to bottle or make jam from all the fruit that had dropped to the ground, Tiana pondered over how she actually demonstrated care for nature in her daily life, and a number of women spoke of needing to "do more". Amy questioned the belief that you can "ring fence something and it will be safe", suggesting instead that environmental care and action needed to occur "within a realistic world picture" that did not tolerate a "materialistic, easy-come easy-go disposable society". Questioning wider societal assumptions and constructions about nature spaces and environmental behaviour was also evident, with topics such as the degradation and pollution of nearby lakes, the changing access to and availability of coastal camping, contemporary land ownership debates, and the consumerism and materialism of society noted. This prompted personal reflection for me, and more specifically, a questioning of the pedagogical approaches and 'direct' experiences in outdoor education that might best contribute to promoting connectedness and care between human and non-human nature.

\section{Issues and implications for outdoor education}

\section{Repeated immersion in everyday local environments}

It has been proposed that extended periods of time outdoors (Rickinson et al., 2004) is important to developing human and non-human nature affinity and connectedness in outdoor education. However the varying life circumstances of women in this study meant that extended, multiday nature-based leisure experiences appeared to be the exception rather than the rule, and had to be carefully planned for if and when they occurred. A distinguishing feature of many women's nature-based interaction was their use of suburban estuarine and bush walkways, backyard gardens, urban parks, and nearby beaches. The accessibility of local nature environs, enabled women to regularly experience 'ordinary' nature through simple leisure, and appeared to cumulatively feed a sense that nature was not just something 'out there', remote and disconnected from women's daily lives. In a similar way, outdoor education teachers in schools also contend with a host of structural and logistical parameters that impinge on their pedagogical decisionmaking. Embracing the potential "power of the proximal" (Payne \& Wattchow, 2008, p. 26), the first pedagogical principle of repeated immersion in everyday local nature environs suggests that 'placing' outdoor education in local contexts just beyond the gymnasium door, may enable the regularity of interaction with nature contexts considered by some (for example Hill, 2010b) to be pivotal to facilitating human and non-human nature connectedness. Adopting Brown's (2010, p. 5) three place-based questions - "What is this place?" "What will it allow?" and "What is my relationship to this place?" productively generates a range of pedagogical approaches that in the first instance, may connect students with 'home'. For instance, in the coastal community in which I live, a 'placed' outdoor education could include repeated opportunities for students to experientially come to know their local beach and coastal environments. Longstanding 
assumptions in outdoor education programming in Aotearoa-New Zealand about the importance of remote or exotic environs (Hill, 2010b), rather than local and 'ordinary', could also be called into question. Furthermore at a very pragmatic level, a deliberate focus on the proximal and local may help alleviate some of the constraints associated with time and financial resources that outdoor education teachers have previously identified as impacting on teaching programmes (for example Hill, 2010a; Zink \& Boyes, 2006).

\section{Decentring traditional performance pedagogies}

Going local however was not the only feature of the holistic nature connectedness evident in these women's accounts. As many descriptions of women's understandings of nature and nature based leisure highlighted, connectedness derived from the physicality and pleasure of moving in nature blended with 'being' in nature. 'Knowing' nature spiritually, emotionally, cognitively, and from historical and cultural perspectives had necessitated a wide assortment of nature-based experiencing and experiences. Implicit in this is the second pedagogical principle- the potent reminder that there may be a need to decentre traditional performance pedagogies in outdoor education if a diverse range of students are to connect with non-human nature during school programmes. While I am not advocating for the removal of traditional adventure experiences or skills-based outdoor pursuits, this principle implies a broadening of the traditional activity base of outdoor education so that there is more room on the pedagogical 'stage' for students to develop an holistic, tacit knowledge of non-human nature. In practice this may necessitate pedagogical approaches that blur traditional boundaries between outdoor education and other subject areas to direct student learning to a more nuanced cultural and historical understanding of the outdoor environment (see Irwin, 2010; Payne and Wattchow, 2008; Slattery, 2001 for examples).

This principle of decentring traditional performance pedagogies also draws attention to the limitations of a 'one size fits all' approach to the sequencing, teaching, and locating of pursuitsbased outdoor education. For example, the provision of student choice and options about the extent and intensity of participation may help to cater for more skilled students for whom 'high adventure' experiences enable positive connection with nature (Martin, 2004). It may also accommodate students who, like some women in this study and students in other research (Martin, 2004, 2005), find that nature takes a backseat in attention in times when personal skills and sense of safety are overly tested. With "...comfort with nature and desire to be in nature" considered to be necessary precursors for developing "ecologically literacy" (Martin, 2008, p. 37), shaping outdoor education experiences so that diverse students enjoy themselves and comfortably build skills is clearly important.

\section{Critical reflection}

The women in this study articulated a love for and connectedness to nature places that spilled over in to care and action in many daily life choices. The third pedagogical principle of critical reflection derives from the women's apparent willingness to ruminate and ask hard questions of 
themselves and others in regards to human and non-human nature connectedness and how this played out in environmentally sensitive actions. For example, when Prue noted the "fictions of nature" wherein "nature was merely commodified and used to sell products to "make us feel good' while ignoring negative impacts on the environment" (Cosgriff, Little, \& Wilson, 2010, p. 24) she demonstrated a questioning of the status quo and of assumptions about appropriate ecological behaviour. Providing a range of opportunities for students to formally and informally reflect on their own and other's embodied understandings of nature, and how these shape and in turn are shaped by their outdoor education experiences, may be a necessary component of human connectedness with non human nature. Slowing down to pause and ponder, to encourage student thinking about where they are, what they are doing, what it means to live simply and 'care-fully' here and in other places (see for example Hill, 2010c), may generate insights for students about their connectedness to nature and impetus for demonstrating care for their own valued nature spaces.

\section{Conclusion}

As Lugg (2007) suggests, the "notion of 'connectedness' is critical to understanding ecological perspectives of the world and of sustainable ways of living in and with the world" (p. 106, italics in original). This paper has drawn on the stories of eleven women who regularly weave nature-based leisure experiences into their daily lives. Each expressed a deeply felt regard for and connectedness to nature and nature spaces, which was evidenced in a range of caring, environmentally attuned leisure and lifestyle actions. In examining these stories of connectedness and care from a pedagogical standpoint, I have teased out three principles that may be integral to promoting a similar human and non-human nature connectedness and care in and through outdoor education.

The 'so what' question of the relevance of women's stories to school-based outdoor education and the lives of school-aged students specifically remains an important one. Arguably it is a question that stands out as one to be 'put to the test' in and through the sharing of stories such as these with students in outdoor education classes. While also mindful of the critiques of applying research conducted with adults to students (see for example Gough, 1999; Gough, N., 1999 in environmental education), I have worked from the premise that these women exemplified lifelong learners and participants in outdoor activities -arguably worthy goals for outdoor educators- and thus have pursued the question of what in their experiences as described might have helped to foster this continuing commitment to and connection with nature. Whether or not such a commitment and connection will provide a useful point of reference in outdoor education is a matter worthy of further professional inquiry. Given the current paucity of research about school-based outdoor education in Aotearoa-New Zealand, research examining students' meanings of nature, their experiences of/in outdoor education, and the potential for particular pedagogical approaches to enable and support learning and connectedness to nonhuman nature from their own standpoint is long overdue. 


\section{References}

Andkjær, S. (2010). Space and place in outdoor education in New Zealand-with a comparative cultural perspective to Friluftsliv in Denmark and the Nordic countries. New Zealand Journal of Outdoor Education, 2(4), 7-25.

Boyes, M. (2000). The place of outdoor education in the health and physical education curriculum. Journal of Physical Education New Zealand, 33(2), 75-88.

Brookes, A. (1994, October). Reading between the lines-Outdoor experience as environmental text. Journal of Physical Education, Recreation and Dance, 29-33.

Brown, M. (2008). Outdoor education: Opportunities provided by a place-based approach. New Zealand Journal of Outdoor Education, 2(3), 7-25.

Brown, M. (2010). Editor's note. New Zealand Journal of Outdoor Education, 2(4), 5.

Brown, M., \& Fraser, D. (2010). Outdoor adventure education: What sorts of risks should we be talking about? Out and About, (23), 9-12.

Brymer, E., \& Gray, T. (2009). Dancing with nature: rhythm and harmony in extreme sport participation. Journal of Adventure Education $\& 3$ Outdoor learning, 9:2, 135 -149.

Cosgriff, M. (2008). What's the story? Outdoor education in New Zealand in the $21^{\text {st }}$ century. Journal of Physical Education New Zealand, 41(3), 14-25.

Cosgriff, M., Little, D., \& Wilson, E. (2010). The nature of nature: How New Zealand women in middle to later life experience nature-based leisure. Leisure Sciences, 32 (1), 15-32.

Flintoff, A., \& Scraton, S. (2001). Stepping into active leisure? Young women's perceptions of active lifestyles and their experiences of school physical education. Sport, Education and Society, $6: 1,5-21$.

Gough, A. (1999). Kids don't like wearing the same jeans as their Mums and Dads: so whose 'life' should be in significant life experiences research? Environmental Education Research, 5:4, 383-394.

Gough, N. (1999). Surpassing our own histories: autobiographical methods for environmental education research, Environmental Education Research, 5: 4, 407-418.

Harrison, M. \& Birrell, C. (2005). An elder speaks: Seeing, reading, feeling the sacred text of the land. In T. J. Dickson, T. Gray, \& B. Hayllar (Eds.), Outdoor and experiential learning: Views from the top (pp. 61-69). Dunedin, New Zealand: Otago University Press.

Hill, A. (2008). Toward a critical outdoor education practice. Ki Waho-Into The Outdoors, 1, 50-52.

Hill, A. (2009). What are we educating for? Ki Waho-Into the Outdoors, 3, 10-14.

Hill, A. (2010a). Reflections on beliefs and practices from New Zealand outdoor educators: Consistencies and conflicts. Australian Journal of Outdoor Education, 14(1), 30-40.

Hill, A. (2010b). Connection to place as a central theme for sustainable outdoor education. New Zealand Journal of Outdoor Education, 2(4), 26-46.

Hill, A. (2010c). Talking the walk: Asking critical questions in outdoor learning experiences. Out and About, 23, 19-20. 
Irwin, D. (2008). Weaving the threads: Challenges encountered while educating for sustainability in outdoor education. New Zealand Journal of Outdoor Education, 2(3), 36-53.

Irwin, D. (2010). Weaving the threads: Exploring identity through bi-cultural outdoor education experiences. New Zealand Journal of Outdoor Education, 2(4), 66-86.

Lugg, A. (2004). Outdoor adventure in Australian outdoor education: Is it a case of roast for Christmas dinner? Australian Journal of Outdoor Education, 8(1), 4-11.

Lugg, A. (2007). Developing sustainability-literate citizens though outdoor learning: possibilities for outdoor education in higher education. Journal of Adventure Education and Outdoor Learning, 7(2): 97-112.

Lynch, P. (2006). Camping in the curriculum. Lincoln University, Canterbury, New Zealand: PML Publications.

MacPhail, A., Collier, C., \& O'Sullivan, M. (2009). Lifestyles and gendered patterns of leisure and sporting interests among Irish adolescents. Sport, Education and Society, 14:3, 281-299.

Martin, P. (2004). Outdoor adventure in promoting relationships with nature. Australian Journal of Outdoor Education, 8(1), 20-28.

Martin, P. (2005). Human to nature relationships through outdoor education. In T. J. Dickson, T. Gray, \& B. Hayllar (Eds.), Outdoor and experiential learning: Views from the top (pp. 28-52). Dunedin, New Zealand: Otago University Press.

Martin, P. (2007). Caring for the environment: Challenges from notions of caring. Australian Journal of Environmental Education, 23, 57-64.

Martin, P. (2008). Teacher qualification guidelines, ecological literacy and outdoor education. Australian Journal of Outdoor Education, 12(2), 32-38.

Matunga, H. (1995). Maori participation in outdoor recreation: An exploration of the research and the issues. In P.J. Devlin, R.A. Corbett, \& C. J. Peebles (Eds.), Outdoor recreation in New Zealand, Vol 1 (pp 17-30). Wellington, New Zealand: Department of Conservation.

Mead, A. (2000). Sacred balance. Global biodiversity assessment: Cultural and spiritual values of biodiversity. United nations Environment program. Retrieved December 12, 2008 from http:// scholar.google.co.nz

Ministry of Education. (1999). Health and physical education in the New Zealand curriculum. Wellington, New Zealand: Learning Media.

Ministry of Education. (2007). The New Zealand curriculum. Wellington, New Zealand: Learning Media.

Ministry of Education. (2008). Te Marautanga o Aotearoa. English translation retrieved November 12, 2010 from http://nzcurriculum.tki.org.nz/Curriculum-documents/Te-Marautangao-Aotearoa.

Ministry of Education. (2009). EOTC guidelines: Bringing the curriculum alive. Wellington, New Zealand: Learning Media.

Payne, P. (2005). Critical experience in outdoor education. In T. J. Dickson, T. Gray, \& B. Hayllar (Eds.), Outdoor and experiential learning: Views from the top (pp. 184-200). Dunedin, New Zealand: Otago University Press. 
Payne, P. \& Wattchow, B. (2008). Slow pedagogy and placing education in post-traditional outdoor education. Australian Journal of Outdoor Education, 12 (10), 25-38.

Preston, L. (2004). Making connections with nature: Bridging the theory - practice gap in outdoor and environmental education. Australian Journal of Outdoor Education, 8 (1), 12-19.

Rickinson, M., Dillon, J., Teamey, K., Morris, M., Mee Young, C., Sanders, D., Benefield, P. (2004). A review of research on outdoor learning. London: National Foundation for Educational Research and Kings College.

Ryan, P. M. (2008). The Raupõ dictionary of modern Mãori. Auckland, New Zealand: Penguin Group.

Slattery, D. (2001). What can environmental history offer outdoor education practitioners? Australian Journal of Outdoor Education, 5(2), 28-33.

Stewart, A. (2008). Whose place, whose history? Outdoor environmental education pedagogy as 'reading' the landscape. Journal of Adventure Education $\mathcal{E}$ Outdoor Learning, 8:2, 79-98.

Straker, J. (2010). Unearthing 'the outdoors' in outdoor education. New Zealand Journal of Outdoor Education, 2(4), 103-112.

Taukamo, R. (2008, Winter). Tu mai rã Hikurangi-Stand tall Hikurangi. Ki waho, 1, 54-55.

Thomas, G. (2005). Traditional adventure activities in outdoor environmental education. Australian Journal of Outdoor Education, 9:1, 31-39.

Thompson, J., Hutson, G., \& Davidson, J. (2008). A case study on environmental perspectives of boulderers and access issues at the Niagara Glen Nature Reserve. Australian Journal of Outdoor Education, 12 (2), 24 - 31.

Wattchow, B. (2008). Moving on an effortless journey: Paddling, river-places and outdoor education. Australian Journal of Outdoor Education, 12(2), 12-23.

Wright, J., MacDonald, D., \& Groom, L. (2003). Physical activity and young people: Beyond participation. Sport, Education and Society, 8:1, 17-33.

Zink, R. (2003). Abseiling at 5, rafting at 10, what do we do with them when they are 15? Why pursuits might seem like an obvious choice for outdoor education. New Zealand Journal of Outdoor Education, 1(2), 56-62.

Zink, R., \& Boyes, M. (2006). The nature and scope of outdoor education in New Zealand schools. Australian Journal of Outdoor Education, 10(1), 11-21.

\section{Notes}

${ }^{1}$ Translations of Mãori words in this paper are from Ryan (2008).

${ }^{2}$ Although referenced in the original journal article (and hence this paper) as Doune MacDonald, I wish to note the correct spelling of Macdonald.

${ }^{3}$ The seven key areas of learning in Health and Physical Education are mental health, sport studies, food and nutrition, sexuality education, body care and physical safety, physical activity, and outdoor education. 
${ }^{4}$ EOTC is a generic term that refers to "all curriculum-based learning and teaching that extends the four walls of the classroom" (Ministry of Education, 2009, p. 4).

${ }^{5}$ The New Zealand Curriculum (Ministry of Education, 2007) applies to all English-medium state and integrated schools where English is the language of instruction. Te Marautanga o Aotearoa (Ministry of Education, 2008) is a parallel curriculum document founded on Mãori principles that applies to Mãori medium schools where Mãori is the language of instruction.

${ }^{6}$ The eight values of The New Zealand Curriculum (Ministry of Education, 2007) are excellence; innovation, inquiry, and curiosity; diversity; equity; community and participation; ecological sustainability; integrity; and respect.

${ }^{7}$ No exact translation of Hauora is given in this document, however the purpose of Hauora is to learn about "total health and wellbeing of spirit, mind, body, and heart, as well as environmental health" (Ministry of Education, 2008, p. 39).

${ }^{8}$ Pãkehã New Zealanders are “non-Mãori, European, Caucasian” (Ryan, 2008, p. 209).

\section{Author notes}

Marg Cosgriff is a Senior Lecturer in the Sport and Leisure Studies department at the University of Waikato. She teaches papers in health and physical education and outdoor education, and has a longstanding interest in learning outdoors. Her research interests include physical education and outdoor education pedagogies in primary and secondary school settings as well as the meanings of nature-based leisure experiences.

\section{Acknowledgments}

I am extremely grateful for the guidance and feedback given by Dawn Penney on the earlier drafts of this paper as well as the helpful feedback from the reviewers. I also wish to acknowledge Donna Little and Erica Wilson my co-researchers in the original study, and the research grant from the Faculty of Education at the University of Waikato that supported the study.

\section{Correspondence}

Marg Cosgriff

Department of Sport and Leisure Studies

The University of Waikato at Tauranga

Private Bag 12027

Tauranga, New Zealand

Email: cosgriff@waikato.ac.nz 